\title{
Viljelykiertokäytännöt peltolohkotilastojen näkökulmasta
}

\author{
Lauri Jauhiainen $^{1)}$ ja Marjo Keskitalo ${ }^{1)}$ \\ ${ }^{1}$ MTT Kasvintuotanto,MTT Planta, 31600 Jokioinen, lauri.jauhiainen@mtt.fi,marjo.keskitalo@mtt.fi
}

\section{Tiivistelmä}

Nyt tehdyssä tutkimuksessa tarkasteltiin maaseutuviraston peltolohkotilastoista viljelyn monimuotoisuutta aluetasolla. Lisäksi tarkasteltiin toteutuneita viljelykiertoja, monokulttuurin yleisyyttä, kuinka viljelykierrot ovat muuttuneet vuosien 1995-2011 aikana ja millaisia eroja tyypillisissä viljelykierroissa ja monokulttuurin yleisyydessä on eri alueiden välillä. Lisäksi tarkasteltiin esikasveja sekä sitä, kuinka monta välivuotta viljelyssä pidetään ennen kuin samalla lohkolla viljellään jälleen samaa kasvia.

Peltolohkotilastoista selvitettiin kunkin kasvulohkon viljelyhistoria mahdollisimman kattavasti. Kasvulohkojen määrä peruslohkon sisällä että peruslohkon pinta-ala vaihteli vuodesta toiseen, kuitenkin pinta-alojen perusteella saatiin selvitettyä varsin kattavasti eri kasvulohkojen viljelyhistoria. Työ vaati paljon tietokoneaikaa, aineistojen ollessa suuria. Kaikilta osin viljelyhistoriaa ei voitu selvittää.

Tulokset osoittavat viljelyn olevan pääosin yksipuolista, mutta selviä eroja löytyi ELY-kestusten välille sekä kuntien välille ELY-keskusten sisällä. ELY-keskusten väliset erot monipuolisuudessa ovat pienentyneet tarkastelujakson 1995-2011 aikana, mutta kuntien väliset erot suurentuneet. Viljely on monipuolistunut tarkastelujaksolla, mutta vain hiukan. Viljelyn yksipuolisuus ja monipuolisen viljelykierron puuttuminen näkyy kasvulohkotasolla selvästi, esikasvina on todennäköisimmin sama kasvi kuin varsinaisena viljelyvuonna. Esimerkiksi nurmen viljelyssä samalla lohkolla viljellään uudestaan nurmea yhden tai korkeintaan kahden välivuoden jälkeen, eikä käytäntö ole muuttunut tarkastelujakson aikana. Merkkejä monipuolistumista on kuitenkin havaittavissa etenkin kevätviljojen viljelyyn erikoistuneilla tiloilla, vaikka ei voida puhua monipuolisesta viljelystä. Esimerkiksi puhtaasta kevätviljojen viljelystä on siirrytty siihen, että viiden vuoden aikana on neljän kevätviljavuoden lisäksi yksi rapsi- tai rypsivuosi. Varsinaista monipuolista viljelykiertoa esiintyy edelleen suhteellisen vähän.

Asiasanat CAP uudistus, maatalouden ympäristötuki, peltolohko tilastot, viljelykierto 


\section{Johdanto}

Viljelykiertojen käyttö on mukana maatalouden ympäristötukien A- ja B- alueiden lisäehdoissa, joiden tavoitteena on viljelyn monipuolistaminen. Tilan peltoalasta saa olla korkeintaan $40 \%$ samalla viljelykasvilla ja yhteensä tilalla tulee viljellä kolmea eri kasvilajia. Nurmia ja kuminaa lukuun ottamatta samaa kasvilajia ei saa viljellä enempää kahta vuotta peräkkäin. Kasvilajeista ainakin yhden tulee olla muuta kuin viljakasvia. Viljelykiertosuunnitelma on tehtävä sopimuksen yhteydessä tilan kasvulohkoille viideksi vuodeksi kerrallaan (Maatalouden ympäristötuen sitomusehdot 2011) Viljelykiertojen lisäämistä ehdotetaan myös CAP uudistukseen liittyvässä tuotannon viherryttämisessä (Euroopan komissio 2010).

Vain osa tiloista valitsee viljelyn monipuolistamisen ja epäselvää onkin ollut se, miten monipuolisesti tai yksipuolisesti peltojamme todellisuudessa viljellään. Viljelykasvivalintoja on aiemmin tarkasteltu ProAgrian Lohkotietopankin aineiston avulla. Kun kevätviljoja tarkasteltiin erikseen, viljeltiin neljän tarkasteluvuoden aikana yleisemmin kolmea viljelykasvia, joista yksi oli muuta kuin viljaa.

Tarkastelussa mukana olleista peltohehtaareista tämä viljelykäytäntö käsitti noin puolet. Tämän lisäksi voitiin erottaa käytännöt, joissa kevätviljojen lisäksi viljeltiin kahta muuta kasvia (27 \% lohkoista) tai pelkästään kevätviljoja (16 \% lohkoista) neljän peräkkäisen vuoden aikana (Keskitalo ym. 2010). Lohkotietopankki perustuu kuitenkin vapaehtoisuuteen, eivätkä tulokset välttämättä kuvaa viljelyn monipuolisuuden todellista tilaa.

Nyt tehtävässä tutkimuksessa tarkastellaan maaseutuviraston peltolohkotilastoista toteutuneita viljelykiertoja, monokulttuurin yleisyyttä, kuinka viljelykierrot ovat muuttuneet vuosien 1995-2011 aikana ja millaisia eroja tyypillisissä viljelykierroissa ja monokulttuurin yleisyydessä on eri alueiden välillä. Tuloksia verrataan maatalouden ympäristötukiehtoihin sekä ProAgrian Lohkotietopankin aineistoon.

Peltolohkotilastoista kerätään kunkin kasvulohkon viljelytiedot viiden vuoden periodeina. Osa kasvulohkoista joudutaan todennäköisesti jättämään pois tarkastelusta kun peruslohkossa kasvulohkot vaihtuivat eikä niiden viljelyhistoriaa voida määrittää varmasti. Viljeltävät kasvit luokitellaan seitsemään kasviryhmään: ohra, kaura, kevätvehnä, syysviljat, öljykasvit, peruna ja palkokasvit. Lisäksi tarkasteltiin erikoiskasveja sekä sokerijuurikasta ja nurmia erikseen.

\section{Aineisto ja menetelmät}

Maaseutuviraston peltolohkotilastoihin on tallennettu vuosittain (1995-2011) kunkin peruslohkon viljelykasvitiedot kasvulohkoittain. Viljelytietoja oli yhteensä yli 20 miljoonaa. Viljelyn monipuolisuus eri alueille (kunta ja ELY-keskus) ja eri vuosina (1995-2011) tutkittiin Shannonin indeksin avulla:

$$
H^{\prime}=-\sum_{i=1}^{S}\left(p_{i} \ln p_{i}\right)-[(S-1) / 2 N]
$$

missä $\mathrm{S}$ on kasvilajien kokonaismäärä, i viittaa kasvilajiin, $\mathrm{S}$ on kasvilajien kokonaismäärä, $\mathrm{N}$ on kasvulohkojen kokonaismäärä, $\mathrm{p}_{\mathrm{i}}$ on kasvilajin suhteellinen esiintyvyys (=kyseisen kasvilajin kasvulohkojen osuus kaikista kasvulohkoista). Maaseutuviraston aineistossa erilaisia kasvilajikoodeja oli n. $200 \mathrm{kpl}$. Koodisto ei on elänyt hiukan vuosien saatossa. Shannonin indeksit laskettiin käyttäen alkuperäisiä kasvikoodeja, että kasvikoodeista yhdisteltyjä ryhmiä jolloin koodistossa tapahtuneet muutokset eivät vaikuta vuosien väliseen vertailuun.

Viljelykierron tarkastelu vaati eri vuosien viljelytilastojen yhdistämistä. Yksi peruslohko saattoi sisältää useampia kasvulohkoja. Kullakin peruslohkolla on peruslohkokoodi, jonka avulla sama peruslohko voidaan tunnistaa eri vuosien tilastoista. Sen sijaan kasvulohkolle ei ole vastaavaa koodia. Lisäksi kasvulohkojen lukumäärä voi vaihdella samalla peruslohkolla vuodesta toiseen. Jotta viljelyhistoria voidaan selvittää, 
täytyy saman kasvulohkon eri vuosien tiedot pystyä yhdistämään. Kasvulohkoista on tiedossa pinta-ala, jonka perusteella nyt selvitettiin sama kasvulohko eri vuosien tilastoista. Pinta-ala ei ollut joka vuosi täsmälleen sama, joten $20 \%$ virhetoleranssi pinta-aloissa hyväksyttiin. Mikäli toleranssin sisällä oli useampi kuin yksi viljelytieto, ei tilastoista otettu mitään viljelytietoa. Mikäli yhden kasvulohkon sisältävä peruslohko oli jaettu useampaan kasvulohkoon seuraavana vuonna, edellisen vuoden peruslohko jaettiin myös useaksi kasvulohkoksi. Vastaava jako tehtiin, mikäli jonain vuonna peruslohkolla oli vain yksi kasvulohko vaikka aikaisempina vuosina kasvulohkoja oli useita. Mikäli kasvulohkojen lukumäärä ja pintaalat vaihtelivat paljon vuodesta toiseen, viljelytietoja ei välttämättä saatu yhdistettyä jonkun vuoden osalta ollenkaan. Tällöin seuraavana vuonna aloitettiin puhtaalta pöydältä aivan kuin kyse olisi uudesta peruslohkosta.

\section{Tulokset ja tulosten tarkastelu}

Kaksisuuntainen ANOVA osoitti, että viljelyn monipuolisuus vaihteli ELY-keskuksesta toiseen $(\mathrm{P}<0.001)$. ELY-keskusten väliset erot olivat muuttuneet lisäksi tarkastelujakson aikana $(\mathrm{P}<0.001)$. Yhdysvaikutus johtui siitä, että Pohjois-Karjalan ja Etlä-Pohjanmaan ELY-keskuksissa viljelyn monipuolisuus oli lisääntynyt enemmän kuin muualla. Monipuolisuusindeksi sai kuitenkin vuosina 2007-2011 suurimmat arvonsa Varsinais-Suomen, Satakunnan, Hämeen, Pirkanmaan ja Etlä-Pohjanmaan ELY-keskuksissa. Matalimman arvot indeksi sai Kainuun ja Lapin keskuksissa. Alkuvuosien (1995-1999) matala indeksin arvo korreloi tilastollisesti melkein merkitsevästi $(\mathrm{P}=0.09)$ suuren muutoksen kanssa. ELY-keskun sisällä kuntien välillä on rajuja eroja indeksin arvoissa. Suurimpia erot olivat Pohjanmaalla, pienimpiä Pirkanmaalla, Etelä-Savossa ja Pohjois-Karajalassa. Kuntien väliset erot ovat kasvaneet aavistuksen tarkastelujaksolla.

Taulukko 1: Viljelyn monipuolisuus (Shanonin indeksin arvo) ELY-keskuksissa vuosina 1995-2011 sekä viiden vuoden keskiarvot jaksoille 1995-1999, 2001-2005 ja 2007-2011.

\begin{tabular}{|c|c|c|c|c|c|c|c|c|c|c|c|c|c|c|c|}
\hline \multirow[b]{2}{*}{ vuosi } & \multicolumn{15}{|c|}{ ELY-keskus } \\
\hline & 1 & 2 & 3 & 4 & 5 & 6 & 7 & 8 & 9 & 10 & 11 & 12 & 13 & 14 & 15 \\
\hline 1995 & 2.05 & 2.14 & 1.97 & 2.03 & 1.88 & 1.90 & 1.76 & 1.65 & 1.61 & 1.69 & 1.82 & 1.52 & 1.49 & 1.29 & 0.77 \\
\hline 1996 & 2.08 & 2.14 & 1.96 & 2.05 & 1.91 & 1.91 & 1.83 & 1.72 & 1.67 & 1.71 & 1.84 & 1.55 & 1.51 & 1.36 & 0.75 \\
\hline 1997 & 1.88 & 1.95 & 1.80 & 1.89 & 1.81 & 1.76 & 1.71 & 1.67 & 1.61 & 1.61 & 1.84 & 1.47 & 1.46 & 1.28 & 0.71 \\
\hline 1998 & 1.90 & 1.94 & 1.83 & 1.89 & 1.85 & 1.77 & 1.73 & 1.73 & 1.66 & 1.64 & 1.88 & 1.49 & 1.55 & 1.44 & 0.74 \\
\hline 1999 & 1.85 & 1.92 & 1.87 & 1.90 & 1.85 & 1.80 & 1.73 & 1.79 & 1.68 & 1.65 & 1.91 & 1.51 & 1.60 & 1.43 & 0.78 \\
\hline 2000 & 1.94 & 2.02 & 1.98 & 2.06 & 2.07 & 1.98 & 2.01 & 2.05 & 1.98 & 1.90 & 2.10 & 1.74 & 1.86 & 1.80 & 1.33 \\
\hline 2001 & 1.92 & 2.04 & 2.00 & 2.04 & 2.07 & 1.98 & 2.05 & 2.06 & 1.99 & 1.95 & 2.13 & 1.80 & 1.93 & 1.80 & 1.32 \\
\hline 2002 & 1.90 & 2.00 & 1.98 & 2.02 & 2.03 & 1.97 & 2.06 & 2.08 & 2.01 & 1.95 & 2.11 & 1.79 & 1.90 & 1.79 & 1.39 \\
\hline 2003 & 1.88 & 2.02 & 1.99 & 2.04 & 2.03 & 1.98 & 2.06 & 2.07 & 1.98 & 1.97 & & 78 & 38 & 1.80 & 1.39 \\
\hline 2004 & 1.92 & 2.03 & 2.02 & 2.04 & 2.10 & 2.01 & 2.06 & 2.06 & 2.00 & 1.97 & 2.14 & 1.85 & 1.88 & 1.87 & 1.38 \\
\hline 2005 & 1.82 & 1.96 & 2.00 & 1.97 & 2.03 & 1.97 & 1.98 & 2.02 & 2.01 & 1.97 & 2.13 & 1.83 & 1.86 & 1.83 & 1.34 \\
\hline 2006 & 1.99 & 2.00 & 2.03 & 2.07 & 2.05 & 2.03 & 1.93 & 1.95 & 1.93 & 1.86 & 2.10 & 1.73 & 1.76 & 1.57 & 0.99 \\
\hline 2007 & 2.01 & 2.02 & 2.01 & 2.07 & 2.05 & 2.02 & 1.88 & 1.90 & 1.91 & 1.80 & 2.10 & 1.69 & 1.75 & 1.54 & 0.98 \\
\hline 2008 & 1.96 & 2.01 & 2.01 & 2.07 & 2.02 & 2.02 & 1.86 & 1.89 & 1.94 & 1.82 & 2.03 & 1.65 & 1.72 & 1.53 & 0.99 \\
\hline 2009 & 1.91 & 1.98 & 2.05 & 2.06 & 2.04 & 2.02 & 1.91 & 1.92 & 1.98 & 1.91 & 2.15 & 1.70 & 1.76 & 1.58 & 1.00 \\
\hline 2010 & 1.96 & 2.22 & 2.10 & 2.14 & 2.11 & 2.07 & 1.90 & 1.87 & 1.94 & 1.87 & 2.22 & 1.76 & 1.78 & 1.58 & 0.96 \\
\hline 2011 & 1.91 & 2.17 & 2.06 & 2.09 & 2.12 & 2.05 & 1.82 & 1.85 & 1.89 & 1.87 & 2.17 & 1.73 & 1.75 & 1.58 & 0.96 \\
\hline \multicolumn{16}{|c|}{ Keskiarvot viiden vuoden jaksoille: } \\
\hline $95-99$ & 1.95 & 2.02 & 1.89 & 1.95 & 1.86 & 1.83 & 1.75 & 1.71 & 1.65 & 1.66 & 1.86 & 1.51 & 1.52 & 1.36 & 0.75 \\
\hline 01-05 & 1.89 & 2.01 & 2.00 & 2.02 & 2.05 & 1.98 & 2.04 & 2.06 & 2.00 & 1.96 & 2.13 & 1.81 & 1.89 & 1.82 & 1.36 \\
\hline 07-11 & 1.95 & 2.08 & 2.05 & 2.08 & 2.07 & 2.03 & 1.87 & 1.89 & 1.93 & 1.85 & 2.13 & 1.71 & 1.75 & 1.56 & 0.98 \\
\hline
\end{tabular}

Tulosten perusteella erot ELY-keskusten välillä ovat pienentyneet (Taulukko 1), mutta kuntien välillä erot ovat kasvaneet. Muutokset ovat olleen yleisesti ottaen maltillisia. Viljelyn on muuttunut hiukan 
monipuolisemmaksi, mutta vain hiukan ja muutos voi johtua joko osittain tai kokonaan kasvilajikoodistossa tapahtuneesta monipuolistumisesta.

Kasvulohkotason tarkastelu osoittaa viljelykierron olevan yksipuolista. Monivuotisten nurmien osalta enemmän kuin joka toinen nurmi perustetaan niin, että tilastoissa näkyy vain yksi välivuosi. Neljäsosassa tapauksista välivuosia on kaksi (Taulukko 2).

Taulukko 2: välivuosien määä kahden monivuotisen nurmen viljelyjakson välissä.

\begin{tabular}{lcccccccccc}
\hline & \multicolumn{10}{c}{ Välivuosia } \\
\cline { 2 - 10 } TE-keskus & $\mathbf{1}$ & $\mathbf{2}$ & $\mathbf{3}$ & $\mathbf{4}$ & $\mathbf{5}$ & $\mathbf{6}$ & $\mathbf{7}$ & $\mathbf{8}$ & $\mathbf{9}$ & $\mathbf{1 0 +}$ \\
Uusimaa & & & & & & & & & & \\
Varsniais-Suomi & 40.5 & 22.0 & 15.4 & 8.5 & 5.0 & 2.6 & 2.0 & 1.5 & 1.1 & 1.5 \\
Satakunta & 48.1 & 21.9 & 15.4 & 8.5 & 5.4 & 2.8 & 2.0 & 1.3 & 0.9 & 1.8 \\
Häme & 22.6 & 12.7 & 6.0 & 3.6 & 2.3 & 1.6 & 0.9 & 0.7 & 1.1 \\
Pirkanmaa & 44.2 & 23.9 & 13.2 & 7.3 & 3.8 & 2.4 & 1.9 & 1.1 & 0.8 & 1.4 \\
Kaakkois-Suomi & 39.1 & 26.7 & 14.3 & 7.6 & 4.9 & 2.6 & 1.8 & 1.1 & 0.7 & 1.2 \\
Etelä-Savo & 44.8 & 24.1 & 13.9 & 6.9 & 3.9 & 2.2 & 1.5 & 1.1 & 0.6 & 1.0 \\
Pohjois-Savo & 46.6 & 29.8 & 12.0 & 5.5 & 2.6 & 1.5 & 0.9 & 0.5 & 0.3 & 0.4 \\
Pohjois-Karjala & 60.7 & 23.5 & 8.6 & 3.4 & 1.6 & 1.0 & 0.6 & 0.3 & 0.2 & 0.2 \\
Keski-Suomi & 52.9 & 26.4 & 10.5 & 4.5 & 2.3 & 1.3 & 1.0 & 0.5 & 0.4 & 0.4 \\
Etelä-Pohjanmaa & 55.8 & 23.4 & 10.2 & 4.4 & 2.2 & 1.5 & 1.0 & 0.6 & 0.4 & 0.5 \\
Pohjanmaa & 48.4 & 22.4 & 12.9 & 6.4 & 3.6 & 2.0 & 1.5 & 1.0 & 0.7 & 1.1 \\
Pohjois-Pohjanmaa & 56.8 & 24.7 & 10.0 & 4.0 & 1.9 & 1.1 & 0.6 & 0.4 & 0.2 & 0.4 \\
Kainuu & 51.1 & 27.0 & 11.0 & 4.6 & 2.5 & 1.6 & 0.8 & 0.7 & 0.4 & 0.5 \\
Lappi & 64.4 & 20.7 & 8.0 & 2.9 & 1.8 & 0.8 & 0.5 & 0.4 & 0.2 & 0.3 \\
& 71.0 & 15.7 & 6.5 & 3.3 & 1.6 & 0.8 & 0.5 & 0.2 & 0.2 & 0.2 \\
Keskimäärin & & & & & & & & & & 0.4 \\
\hline
\end{tabular}

Taulukko 3: Prosenttiosuus peltohehtaareista joissa esikasvi on sama kuin viljelyvuoden kasvi. Prosenttiosuudet on laskettu kolmena ajanjaksona erikseen.

\begin{tabular}{lrrr}
\hline & \multicolumn{3}{c}{ jakso } \\
\cline { 2 - 4 } Kasvi & $\mathbf{1 9 9 5 - 1 9 9 9}$ & $\mathbf{2 0 0 1 - 2 0 0 5}$ & $\mathbf{2 0 0 7 - 2 0 1 1}$ \\
Tärkkelysperuna & 75.80 & 76.59 & 71.43 \\
Sokerijuurikas & 69.26 & 67.30 & 53.88 \\
Ruokaperuna & 64.62 & 67.25 & 68.57 \\
Rehuohra & 57.18 & 56.78 & 59.62 \\
Kaura & 51.98 & 57.59 & 53.21 \\
Kevätvehnä & 49.94 & 44.35 & 37.69 \\
Mallasohra & 39.67 & 48.07 & 42.82 \\
Syysvehnä & 32.12 & 23.08 & 17.07 \\
Syysruis & 14.95 & 17.43 & 12.58 \\
Kevätrypsi & 11.78 & 11.10 & 5.47 \\
Ruisvehnä & 7.31 & 10.83 & 19.14 \\
Ruokaherne & 3.98 & 2.79 & 1.27 \\
Rehuherne & 2.79 & 4.94 & 3.11 \\
Kevätrapsi & 1.83 & 1.51 & 1.56 \\
\hline
\end{tabular}

Esikasvien tarkastelu osoitti useilla kasveilla viljelyn olevan yksipuolista: tyypillisin esikasvi oli sama kuin viljelyvuoden kasvi. Perunalla ja sokerijuurikkaalla näin oli yli 50\% peltoalasta (Taulukko 3). Myös viljoilla osuudet olivat suuria. Kevätrypsilläkin osuus ylitti 10\% sekä tarkastelujaksolla 1995-1999 että 
jaksolla 2001-2005. Sen sijaan jaksolla 2007-2011 osuus oli puolittunut. Koko aineistoa tarkasteltaessa on havaittavissa trendi, että esikasviksi on yhä harvemmin sama kuin viljelyvuoden kasvi. Muutos on pieni ja yksittäisillä kasveilla muutos on vastakkainen (Taulukko 3). Viljoilla ja perunalla viljelykiertojen tarkastelu osoittaa samaa kuin esikasvitarkastelu: monokulttuuria esiintyy paljon ja monokulttuurin yleisyys on ajan kuluessa pysynyt sama tai hiukan vähentynyt.

\section{Johtopäätökset}

ELY-keskusten väliset erot viljelyn monipuolisuudessa ovat pienentyneet, vaikkakin kuntien väliset erot kasvaneet. Peltolohkotasolla on nähtävissä, että viljely ei ole monipuolista eikä viljelykiertoihin liittyviä suosituksia noudateta. Vuosien 1995-2011 aikana tilanne ei ole olennaisesti muuttunut, mutta monet suureet kertovat, että yksi askel on otettu viljelyn monipuolisuuden suuntaan.

\section{Kirjallisuus}

Euroopan komissio 2010. Komission tiedonanto Euroopan parlamentille, neuvostolle, Euroopan talousja sosiaalikomitealle ja alueiden komitealle. Yhteinen maatalouspolitiikka vuoteen 2020: Ruoka, luonnonvarat ja alueiden käyttö - miten hallita tulevat haasteet?

Keskitalo, M., Jauhiainen, L., Peltonen, S. 2010. Viljan oikea esikasvivalinta lisää satoa ja kannattavuutta. Maaseudun Tiede 67, 1(15.3.2010): 6.

Maatalouden ympäristötuen sitomusehdot 2011.

2011http://www.mavi.fi/fi/index/viljelijatuet/maataloudenymparistotuki.html 